\title{
THE CHRISTIAN ORTHODOX CHURCH FASTING: NUTRITION AND HEALTH
}

\begin{abstract}
Drd. Nikolaos E. RODOPAIOS
School of Pastoral and Social Theology of the Christian Archaeology and Arts of the Aristotle University of Thessaloniki, Greece

Faculty of Medicine of the School of Health Sciences of the University of Crete, Greece

https://doi.org/10.47433/tv.xcvn9-12.35

Abstract

The Christian Orthodox Church fasting is very important and necessary in the lives of believers, because besides the fact that it is a divine command it is also an expression of austerity, which generally characterizes spiritual life but it is also a conscious act of abstaining from specific foods and an exercising of the temperance. The present study aimes to investigate whether adherence to Christian Orthodox Church fasting affects in health of human. The Christian Orthodox Church fasting diet involves an eating pattern according to which fasting individuals decide to go extended and shorttime periods of abstinence from animal-based energy-rich products, with intervening periods of normal food intake. These fasting periods are repeated with the same sequence every year, and when added, they cover half a calendar year (178 \pm 19 days). The periodic abstinence from dairy and, in general, animal products does not seem to harm the health of the people, not only the adults but also and the children. The Christian Orthodox Church fasting diet has an independent positive effect on cognition and emotional wellbeing in middle aged and elderly individuals.
\end{abstract}

Keywords: Fasting Orthodox Church, nutrition, diet, health.

\section{Characteristics and specific features of Christian nutritional culture}

In orthodox Christian practice, fasting is particularly prominent, an expression of austerity and unnecessary avoidance, which generally characterizes spiritual life. The fasting is not just an abstention or a measure of eating particular foods, but it is directly related to the virtue of temperance. Saint Cyril of Jerusalem reports that the purpose of physical fasting is to heal the flesh and the passions ${ }^{1}$.

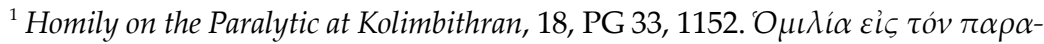

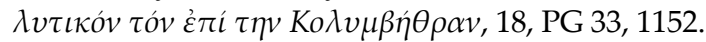


Those who follow a fasting diet receive many benefits, which are why Saint John Chrysostom explains that the price of fasting is not abstinence from food but, above all, abstinence from sins ${ }^{2}$.

Thus in the Christian living standard, temperance is employed in removing the original choice of gluttony. In other words, man is called to restrict food, the consumption of which by the Adam and Eve (First People created, Protoplast) gave rise to exile from paradise. A consumption that accompanied disobedience to the divine command (fall - sin) and plunged all mankind into the darkness of tarnishing the image of God created man. Only after the Son has been humanized has man regained the ability to return to paradise, now following the opposite path.

What he once ate and condemned him is now suppressed to save him. Food and drink control is the principle of mind control ${ }^{3}$. Fasting and temperance, which are generally erased by modern man, not only help enslave the carnal mind and free the body from the tyrannical bonds of carnal mind, but at the same time brightens the mind as well.

According to the Fathers, the partial purity of the soul, through prudence, is achieved by fasting and moderation. The fast of the Orthodox Church can be described as partially vegetarian, that is, it is formed in four periods per year, each lasting 15 or 40 days, without causing severe nutritional deficiencies, such as that of vegetarians. However, "abortive" abstinence periods have also been established, i.e. periods during which all types of food are consumed (Absolute or Free Periods), especially after or before fasting (40 days) a process that allows the human body to cover any it's nutritional needs, which were probably presented during the long fasting periods.

In general, fasting focuses on avoiding animal foods, in other words meat, eggs, and dairy products, while oil, wine and fish are sometimes allowed. Reduced consumption of saturated fat (animal) is beneficial to health, as is increased consumption of vegetables, fruits and legumes, foods characteristic of the church diet.

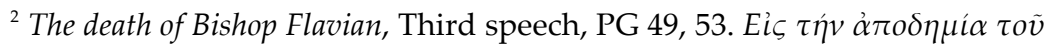

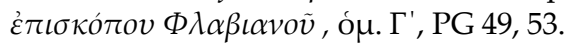

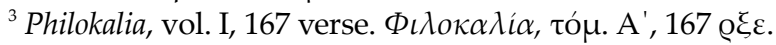


Another characteristic of fasting is the consumption of fish, which is sometimes obligatory. Fish is a staple food to meet the nutritional requirements and helps replenish the protein we lack in meat. The same is true of seafood, which is allowed in all fasts and is high in nutrition, along with fish, because it provides the body with valuable omega-3 fatty acids, which exert beneficial effects on the cardiovascular system and protect the immune system of the organism.

The most deprived period in terms of food avoidance for a long time is that of the Great Forty, but there is an endless variety of seasonal foods that can be used in this fasting, so that there is no chance of nutrient deficiency. Also, another specialty of fasting is the days of Wednesday and Friday, which are characterized as strict fasting days (oil and wine consumption is forbidden), while Wednesday is in the middle of the week and allows the human body to avoid overeating, while Friday is before the weekend, where larger calorie meals are also consumed.

Consequently, weekly fasting helps maintain and balance a body's calorie intake at normal levels and avoids over-calorie intake per week by providing a balanced diet. The measure of consumption, which is required by fasting, also contributes to health in the sense of avoiding over-consumption and obesity. Ecclesiastical nutrition, as it has been established until today, is governed by the principles of the Mediterranean diet, which has a positive effect on human health and has proven to be one of the healthiest diets in the world. Many of the foods that are integral to the Mediterranean diet are also foods consumed during the fasting season (oil, olives, legumes, bread, vegetables, fruits, nuts, wine).

\section{Fasting and health effects of human body}

\subsection{How does fasting affect in health}

Fasting is reported to be a non-pharmacological intervention to improve health and increase longevity ${ }^{4}$. The fasting of the Orthodox Church has unique dietary recommendations that prompt

\footnotetext{
${ }^{4}$ Trepanowski J.F., Bloomer R.J., The impact of religious fasting on human health, in "Nutrition Journal", vol. 9, 2010, p. 57.
} 
a periodic vegetarian diet, with characteristics of the well-known Mediterranean $\operatorname{diet}^{5,6,7}$.

The Orthodox Church's dietary guidelines recommend an annual abstinence from dairy products, meat and eggs for a total of 159 to 197 (SD: $178 \pm 19$ ) days ${ }^{8}$.

Nutrition in the Orthodox Christian Church is characterized by increased consumption of fruits and vegetables, fish and seafood and legumes, which provide protective action against many chronic diseases ${ }^{9}$, as well as reduced consumption of saturated fat (dairy products) and dietary cholesterol ${ }^{10}$.

In particular, the Department of Social Medicine, Preventive Medicine and Nutrition of the Medical School of the University of Crete in Greece, has been involved in the study of the relationship between the fasting of the Orthodox Church and health. They are the first studies dealing with and presenting the overall picture of the effect of periodic vegetarianism on various diseases, which are followed by believers of the dietary rules of the Orthodox Church in a range of biochemical and biological parameters.

In one of these studies, they show that dedication to the fasting periods of the Christian Orthodox Church contributes to a decrease in blood lipid profile and body weight and in general to the beneficial effect on lipoprotein profile and prevalence of obesity. More specifically, 120 Greek adults (20-60 years old), 60 fasters and 60 non-fasters from the region of Heraklion, Crete, were followed

${ }^{5}$ Kafatos A., Kouroumalis I., et al., Coronary-heart-disease risk-factor status of the Cretan urban population in the 1980s, in "American Journal of Clinical Nutrition", vol. 54, 1991, pp. 591-598.

${ }^{6}$ Trichopoulou A., Kouris-Blazos A., et al., Diet and overall survival in elderly people, in "British Medical Journal", vol. 311, 1995, pp. 1457-1460.

${ }^{7}$ Sarri K.O., Linardakis M.K., et al., Greek Orthodox fasting rituals: a hidden characteristic of the Mediterranean diet of Crete, in "British Journal of Nutrition", vol. 92, 2004, pp. 277-284.

${ }^{8}$ Rodopaios N.E., et al., Is periodic abstinence from dairy products for half a year, detrimental to bone health of children and adolescents?, in "Austin Journal of Nutrition and Food Sciences", vol. 5, 2017, p. 1094.

${ }^{9}$ Whorton J.C., Historical development of vegetarianism, in "American Journal of Clinical Nutrition", vol. 59, 1994, pp. 1103S-1109S.

${ }^{10}$ Papadaki A., Vardavas C., et al., Calcium, nutrient and food intake of Greek Orthodox Christian monks during a fasting and non-fasting week, in "Public Health Nutrition", vol. 11, 2008, pp. 1022-1029. 
longitudinally for one year. Sixty fasted regularly in all fasting periods (fasters) and $60 \mathrm{did}$ not fast at all (controls). The three major fasting periods under study were: Christmas (40 days), Lent (48 days) and Assumption (August, 15 days). Statistically significant end-fasting total and LDL ${ }^{11}$ cholesterol differences were found in fasters. Fasters compared to controls presented $12.5 \%$ lower endtotal cholesterol, $15.9 \%$ lower end-LDL cholesterol and 1.5\% lower end-BMI ${ }^{12}$. The end-LDL/HDL ratio was lower in fasters $(6.5 \%)$ while the change in end-HDL cholesterol ${ }^{13}$ in fasters $(4.6 \%$ decline) was not significant. Similar results were found when the preand end-fasting values of fasters were compared. No change was found in non-fasters subjects ${ }^{14}$.

In a newer study, greater decreases in total cholesterol were observed in $17.8 \%$ and LDL in $31.4 \%$, respectively, at the end of the Holy Week before Easter, in monks in Heraklion, Crete ${ }^{11}$.

More recent studies in Mount Athos monasteries have found in addition to the above reductions in lipid levels and the optimum profile in regulating blood glucose in a benign period ${ }^{15}$ and lower body weight and lower insulin resistance, which is particularly favorable to the avoidance of many non-communicable diseases characterized by chronic inflammation ${ }^{16}$.

In another study of the University of Crete, mainly in priests and nuns, has shown that religious fasting contains only $6 \%$ of total cholesterol and saturated fat content, while being high in antioxidant

${ }^{11}$ Low Density Lipoprotein (LDL) cholesterol is often called the "bad" cholesterol because it collects in the walls of your blood vessels, raising your chances of health problems like a heart attack or stroke.

${ }^{12}$ Body mass index (BMI) is a measure of body fat based on height and weight that applies to adult men and women.

${ }^{13}$ High Density Lipoprotein (HDL) cholesterol is known as the "good" cholesterol because it helps remove other forms of cholesterol from your bloodstream. Higher levels of HDL cholesterol are associated with a lower risk of heart disease.

${ }^{14}$ Sarri K.O., Tzanakis N.E., et al., Effects of Greek Orthodox Christian Church fasting on serum lipids and obesity, in "BMC Public Health", vol. 3, 2003, p. 16.

${ }^{15}$ Karras S.M., Persynaki A., et al., Health benefits and consequences of the Eastern Orthodox fasting in monks of Mount Athos: a cross-sectional study, in "European Journal of Clinical Nutrition", vol. 71, 2017, pp. 743-749.

${ }^{16}$ Karras S.M., Koufakis T., et al., Christian Orthodox fasting in practice: A comparative evaluation between Greek Orthodox general population fasters and Athonian monks, in "Nutrition", vol. 59, 2019, pp. 69-76. 
vitamins; and suggest that promoting the dietary guidelines of the Christian Orthodox Church could have long-term health benefits, and can be an effective public health promotion strategy in this population as it would be easier for individuals to follow ${ }^{17}$.

A recent observational study in the journal Archives of Osteoporosis, investigated whether adherence to Christian Orthodox Church fasting, affects bone health and the prevalence of osteoporosis in older individuals. Participants were 200 men and women, of whom 100 had been following the fasting rules of the Christian Orthodox Church for a median of 31 years and 100 were non-fasters, all aged 50 to 78 years. Despite lower calcium intake and lower consumption of dairy and soy products, older individuals adhering to Christian Orthodox Church fasting did not differ in bone health $(\mathrm{BMD} \& \mathrm{BMC})^{18}$, or prevalence of osteoporosis from the non-fasters.

Thus, periodic abstinence from dairy and, generally, animal products does not seem to compromise bone health in older individuals ${ }^{19}$.

Another study in the same subject discovered that the overall lumbar spine osteoporosis incidence was as low as 9\% (18 individuals out of 200), namely $4 \%$ of fasters and the - more than three times higher $-14 \%$ of non-fasters ${ }^{20}$.

At the same time, periodic vegetarian diet, as is essentially fasting, prevents chronic diseases such as cardiovascular disease, hypertension, type 2 diabetes mellitus and various forms of cancer. The diet recommended by the Orthodox Church ideally combines the benefits of a vegetarian and a vegetarian diet, avoiding the health risks of strict vegetarianism ${ }^{21}$.

${ }^{17}$ Sarri K., Bertsias G., et al. The effect of periodic vegetarianism on serum retinol and a-tocopherol levels, in "International Journal for Vitamin and Nutrition Research", vol. 79, 2009, pp. 271-280.

${ }^{18}$ BMD: Bone Mineral Density \& BMC: Bone Mineral Contest.

${ }^{19}$ Rodopaios N.E., Mougios V., et al., Effect of periodic abstinence from dairy products for approximately half of the year on bone health in adults following the Christian Orthodox Church fasting rules for decades, in "Archives of Osteoporosis", vol. 14, 2019, p. 68.

${ }^{20}$ Rodopaios N.E., Manolarakis G.E., et al., The significant effect on musculoskeletal metabolism and bone density of the Eastern Mediterranean Christian Orthodox Church fasting, in "European Journal of Clinical Nutrition", 2020 (in press).

${ }^{21}$ Karras S.M., Persynaki A., et al., Health benefits and consequences of the Eastern Orthodox fasting in monks of Mount Athos: a cross-sectional study, pp. 743-749. 
Frequent seafood consumption throughout the year, as religious fasting suggests, as well as the almost exclusive consumption of olive oil protect against cardiovascular events. "The drop in lipids with fasting is comparable to that of modern medicine. The reduction of bad cholesterol is similar to that of medicines (statins), but without the side effects of drugs, such as the effect on the liver, the increased risk of cancer etc.", says Dr. Antonios Kafatos, Professor of Preventive Medicine and Nutrition, of the University of Crete and responsible for research on the fasting of the Orthodox Church ${ }^{22}$.

There are a number of studies showing the benefits of avoiding animal products to the general population. High meat consumption (in developed countries are $23 \mathrm{~kg}$ meat / capita) is the major cause of the development of several types of cancers, such as colon, lung, pancreas, esophagus and liver ${ }^{23}$.

In summary, while higher intake of animal protein was associated with higher mortality and plant protein was associated with lower mortality, these associations were confined to participants with at least one lifestyle risk factor (cardiovascular, cancer, all cause and other). Substitution of plant protein for animal protein, especially from processed red meat, may confer a substantial health benefit.

Therefore, public health recommendations should focus on improvement of protein sources ${ }^{24}$. Also, in recently review article, when major protein sources were compared, consumption of processed red meat had significantly higher mortality in all-cause than consumption of plant-based sources of protein ${ }^{25}$.

In Greece according to the Statistical Service for 2017, the average monthly expenditure of households for the purchase of meat is $23 \%$ higher than any other type of food, while the average monthly consumption of meat for the period 2013-2017 is constantly above $10 \mathrm{~kg}$. While fish consumption is quite low (about 7\%), although it

22 "THE NEWS" Newspaper of Greece, How Fasting Affects Health, (in Greek), from Roula Tsoulea, 14 April 2011.

${ }^{23}$ Genkinger J.M., Koushik A., Meat consumption and cancer risk, in "PLoS Medicine", vol. 3, 2007, p. 345.

${ }^{24}$ Song M., Fung T., et al., Animal and plant protein intake and all-cause and causespecific mortality: results from two prospective US cohort studies, in "JAMA Internal Medicine", vol. 176, 2016, pp. 1453-1463.

${ }^{25}$ Willett W.C., Ludwig D.S., Milk and Health, in "The New England Journal of Medicine", vol. 382, 2020, pp. 644-654. 
should have been higher, since Greece is a coastal and island country, surrounded by the sea and having increased fish production.

Therefore, fasting can also help prevent this by avoiding frequent consumption of meat and generally saturated fat (dairy products), which are major causes of health problems and increased consumption of fish and seafood in most fasting periods, which have sufficient health benefits because they have omega- 3 fatty acids.

Another study by the University of Crete, published in the "British Journal of Nutrition", showed that religious fasting is part of traditional Cretan diet, which has contributed to the excellent health of Cretans in previous decades (as found in the Study of Seven Countries). Dietary analyzes have shown that during fasting study fasters reduce energy intake but improve their dietary content by reducing total fat, saturated fat, cholesterol, protein and increased fiber intake, folic acid dietary iron, carbohydrates, fruits and vegetables and legumes.

Therefore, due to the high intake of fiber (27.7-38.7 grams) from the frequent consumption of fasting, fruits and vegetables, fasting does not face problems with constipation ${ }^{26}$.

Exclusive vegetarian and vegan have an increased risk for cardiovascular events due to vitamin B12 deficiency and high levels of homocysteine ${ }^{27}$.

Fasting also has benefits in the heart. "The proposal of fasting for fish consumption over many years has been formally justified by the latest scientific research showing that fish oils are the only animal fats that protect our vessels", says Professor of Cardiology, Dr. Toutouzas Paulos and Director of the Greek Cardiology Foundation. And he explains that "the abundance of antioxidants found in greens and other plant foods has been proven to protect our heart from the atherosclerotic plaque that blocks it"28.

Also fasting has no observable effect on blood pressure despite significant changes in nutrient and mineral intake and in combination with weight reduction, normally associated with reduced

\footnotetext{
${ }^{26}$ Karras S.M., Koufakis T., et al., Christian Orthodox fasting in practice: A comparative evaluation between Greek Orthodox general population fasters and Athonian monks, in "Nutrition", vol. 59, 2019, pp. 69-76.

${ }^{27}$ Craig W.J., Health effects of vegan diets, in "American Journal of Clinical Nutrition", vol. 89, 2009, pp. 1627S-1633S.

${ }^{28}$ Genkinger J.M., Koushik A., Meat consumption and cancer risk, p. 345.
} 
blood pressure. This proved a study on blood pressure control in 28 devout Orthodox Christian fasters and 29 matched controls living in Crete, Greece, were followed for 1 year during 2001. Blood pressure data were gathered before (pre) and near completion (end) of the three major fasting periods of the Orthodox Christian calendar [Christmas (40 days)-Easter (48 days)-Assumption (15 days)] along with other information on their dietary and lifestyle habits, body measurements and blood samples ${ }^{29}$.

Several studies in recent literature refer to the effects of nutrition and religious fasting on blood coagulation, one of them investigated whether the 48 days that Orthodox Christians fast prior to Easter affects blood coagulation. The studied sample consisted of 41 volunteers, aged 20-55 years, who fasted and abstained from animal products for 48 days. In conclusion, the blood coagulation is not affected by Orthodox Christian fasting, as the balance between the exogenous and the endogenous coagulation pathways does not change. This fact can be attributed to two possible mechanisms: a) low consumption of animal fatty acids has beneficial effects on the exogenous coagulation pathway, b) the endogenous coagulation pathway appears to show greater activation post-fasting, even the lower fibrinogen levels. The mechanism of this activation is still unknown and needs to be elucidated ${ }^{30}$.

The same results were found in another recent study in Thessaloniki in 35 healthy individuals (19-66 years old) after the end of the same fasting period, as in the study above. Also, the Orthodox Christian fast impairs all haematological and coagulation parameters and seems to be beneficial in antioxidant protection and show might to help in the prevention of cardiovascular diseases ${ }^{31}$.

In children, the Christian Orthodox Church fasting does not prevent the smooth development, nor does it reduce their activity. This investigated a cross-sectional study among 609 children between 5 and 15.5 years old, from a private school in Thessaloniki,

${ }^{29}$ Sarri K., Linardakis M.K., et al., Does the periodic vegetarianism of Greek Orthodox Christians benefit blood pressure?, in "Preventive Medicine", vol. 44, 2007, pp. 341-348.

${ }^{30}$ Liali M., Mpirintzis L., et al., The effects of Orthodox Christian fasting on blood coagulation, in "International Journal of Biomedical Laboratory Science", vol. 4, 2015, pp. 39-43.

${ }^{31}$ Makedou K.G., Vagdati E., et al., Total antioxidant capacity, haematological and coagulation Parameters after Orthodox Christian fast, in "Macedonian Journal of Medical Sciences", vol. 6, 2008, pp. 284-286. 
Northern Greece; $12.1 \%$ of them followed all fasting periods and $43.3 \%$ fasted partially shows that Children who adhere to the fasting periods appear to be closer than non fasting children to the recommended daily nutrient intake, with the exception of two nutrients, magnesium and vitamin $\mathrm{E}$.

Non-fasting children had significantly higher energy intake, saturated fat, harmful trans-fatty acids, and cholesterol than children who fasted fully or partially. No significant differences were found in iron calcium, and vitamin A.

The findings, according to the scientists in their report, are in agreement with a study in adults who observed fasting that showed that iron intake was not lower during fasting because it was replenished by vegetable foods rich in iron, such as legumes, nuts, shellfish, tahini (sesame paste) and fortified cereals. And no significant difference was observed in the growth rate between children who fasted and those who did not fast at any period ${ }^{32}$.

In a recent cross-sectional study included 200 healthy men and women, aged 18-35, of whom 100 had been following religious fasting for a median of 14 years, starting at the age of 10, and 100 were non-fasters; found that the fasters had no problems with their bone health and their bone growth was similar to that of non-fasters. Despite lower calcium intake and lower dairy product consumption, individuals adhering to religious fasting since childhood did not differ in height, bone mineral density and content, or prevalence of fractures from non-fasters.

Therefore, periodic abstention from dairy and, generally, animal products since childhood does not seem to compromise bone health in young adults ${ }^{33}$.

Thus proving that one can follow the fasting of the Christian Orthodox Church from childhood without having a health problem in his bones and development in adulthood.

Study proves that the fasting of the Christian Orthodox Church reduces the incidence of depression. Adherence to the Orthodox

${ }^{32}$ Chryssochoou E., Linardakis M., et. al., The effect of Christian Orthdox Church fasting on the health and growth of children and adolescents [Article in Greek], in "Paediatriki", vol. 73, 2010, pp. 121-129.

${ }^{33}$ Rodopaios N.E., Mougios V., et al., Bone status of young adults with periodic avoidance of dairy products since childhood, in "European Journal of Pediatrics", vol. 179, 2020, pp. 645-651. 
Christian diet, which allows for the frequent consumption of fish and seafood, is associated with increased levels of omega-3 fatty acid (DHA) adipose tissue, which is associated with lower chances of developing depressive symptoms, better mental function, and protection against various chronic diseases ${ }^{34}$.

Also, a recent study investigates the effects of the Christian Orthodox Church Fasting diet, on the cognitive function and emotional wellbeing of normal middle aged individuals. 105 fasting individuals and 107 non-fasting individuals were evaluated regarding their cognitive performance and the presence of anxiety and depression using the Mini Mental Examination Scale, the Hamilton Anxiety Scale and the Geriatric Depression Scale (GDS). The Christian Orthodox Church Fasting diet has an independent positive effect on cognition and emotional wellbeing in middle aged and elderly individuals. The beneficial effects of fasting should inform lifestyle choices of people seeking to live well and gracefully grow older ${ }^{35}$.

In conclusion, studies show that diet quality may be better for fasters. Intake of total fat, saturated fat and trans fatty acids is lower in both adults and children fasters, while intake of protective nutrients such as vitamin C, folate, magnesium, and fiber is higher and provides protection from many chronic diseases. The weight (BMI) and obesity levels drop during the fasting period. The lipid profile (total cholesterol, LDL, HDL, triglyceride) is generally more favorable in fasters.

In general, fasting of the Christian Orthodox Church has a beneficial effect on the human body and should be promoted as a healthy way of life to avoid various diseases, but also to contribute to better mental health ${ }^{36}$.

${ }^{34}$ Sarri K.O., Linardakis M., et al., Adipose DHA inversely associated with depression as measured by the Beck Depression Inventory, in "Prostaglandins, Leukotrienes and Essential Fatty Acids", vol. 78, 2008, pp. 117-122.

${ }^{35}$ Spanaki K., Rodopaios N.E., et al., The Christian Orthodox Church Fasting diet is associated with lower levels of depression and anxiety and a better cognitive performance in middle life, in "European Journal of Ageing", 2020 (in press).

${ }^{36}$ Lazarou C., Matalas A.-L., A critical review of current evidence, perspectives and research implications of diet-related traditions of the Eastern Christian Orthodox Church on dietary intakes and health consequences, in "International Journal of Food Sciences and Nutrution", vol. 61, 2010, pp. 739-758. 


\subsection{If deficiencies of various nutrients are observed during fasting}

After what has been said about Christian Orthodox fasting, the legitimate question for many is whether someone who fasts so many days a year or for a long time, such as Lent, can have a complete and balanced diet, and to what extent he gets all the nutrients he needs to live, and if he does, doesn't cause any damage to his body?

Diets followed by religious belief have the characteristic of a vegetarian $\operatorname{diet}^{37}$. Exclusive vegetarian and vegan have deficiencies in vitamin B12, deficiencies in vitamin D, calcium, omega-3 fatty acids and in some cases iron and zinc ${ }^{38}$. Thus, they are at increased risk for cardiovascular events and osteoporosis, and are more likely to have iron deficiency.

As has already been mentioned, fasting of the Orthodox Church is characterized as a vegetarian diet, but it is periodic and is a model of the Mediterranean diet; however, no deficiencies in macronutrients such as vegetarians have been observed, nor during fasting periods.

\subsubsection{Protein (amino acids)}

The human body needs a known proportion of proteins, carbohydrates and fats (macronutrients) per kilogram of body weight ${ }^{39}$. Macronutrients are the main components of the food that our body builds, but they are also sources of energy (the "fuel") for the body's functions. The amounts needed by each human body to cover its needs in macronutrients varies and depends on many factors such as the existing weight, age, gender, height.

But with regard to fasting, the major challenge lies in meeting the body's needs for high quality proteins that are mostly found in

\footnotetext{
${ }^{37}$ Sabate J., Religion, diet and research, in "British Journal of Nutrition", vol. 92, 2004, pp. 199-201.

${ }^{38}$ Craig W.J., Health effects of vegan diets, in "American Journal of Clinical Nutrition", vol. 89 (suppl), 2009; pp. 1627S-1633S.

${ }^{39}$ Proteins are essential nutrients for the human body. They are one of the building blocks of body tissue and can also serve as a fuel source. As a fuel, proteins provide as much energy density as carbohydrates: $4 \mathrm{kcal}$ (17 kJ) per gram; in contrast, lipids provide $9 \mathrm{kcal}(37 \mathrm{~kJ})$ per gram. Nelson, David L., Cox, Michael M., Principles of Biochemistry (4th ed.), W.H. Freeman, New York, 2005.
} 
animal foods (meat, fish, milk, cheese, eggs). These animal proteins make up $65 \%$ of the protein the body needs and cannot synthesize on its own from other amino acids.

Amino acids are generally chemicals containing except carbon, oxygen, hydrogen and nitrogen (16\%). There are numerous amino acids in nature, about 200, but the most interesting are 20, which are used to make most proteins of the living organisms on Earth. These are called protein amino acids and are essential building blocks of the protein. In the human adult, 9 of the 20 amino acids used in the synthesis of proteins cannot be synthesized by the body and must be obtained from food, therefore called essential or basic amino acids (methionine, lysine, threonine, valine, leucine, tryptophan, cysteine, phenylalanine, and tyrosine $)^{40,41}$.

There are animal proteins and vegetable proteins based on their origin. The foods from animal proteins are "high biologically valuable" foods because they exceed the needs of essential amino acids, such as the $\mathrm{egg}^{42}$.

According to Dr. Avramidis (cardiologist, Professor of Pathology at the University of Athens) the problem of reducing animal protein in fasting is much simpler for the following reasons:

- The fasting according to the Christian Orthodox Church is not all the same as already mentioned. The "stringency" of each fast varies, so not all fasting are the same so although they are several days a year they differ.

- When fasting is strict, that no olive oil is permitted (such as Lent before Easter and the fast of Virgin Mary), foods such as olives, tahini, nuts, etc. are allowed.

- When meat is not allowed, fish are allowed (such as Christmas fasting and the fast of Twelve Apostles). So the fasting diet has animal protein.

- But even in cases where fish are not allowed, the mollusks such as octopus, squid; the shellfish such as oysters, mussels; the crustaceans such as shrimp, crabs, crayfish, etc. which they are all

${ }^{40}$ Elmore D.T., Barrett G.C., Amino acids and peptides, Cambridge University Press, Cambridge, UK, 1998, pp. 48-60.

${ }^{41}$ Jakubke H., Sewald N., Amino acids, Peptides from A to Z: A Concise Encyclopedia, Wiley-VCH, Germany, 2008, p. 20.

${ }^{42}$ Fennema O.R., Food Chemistry, 3rd edition, CRC Press, 1996, pp. 327-328. 
sources of animal protein and allowed to eat during to the all fasting periods.

- Vegetable foods, if combined properly, are a complete meal as they provide essential high-quality amino acids that cover the needs of the body even during periods of fasting, such as lentil and rice ( $\varphi \alpha \kappa o ́ \rho v \zeta o)$ and generally a combination of legumes and cereals.

Many amino acids are created (synthesized) from other amino acids by a process called transamination, although most organisms receive the essential amino acids through food. The lack of essential amino acids of one protein of one food can be complemented with the essential amino acids of the other protein of another food (protein complement) ${ }^{43}$.

The minimum amount of amino acids supplied by the body in relation to its needs ("limit" amount of amino acids) varies according to the type of vegetable food such as in the corn, the content of tryptophan and lysine, in the wheat, the content of lysine and in the cereals, the content of methane $\mathrm{e}^{44,45}$.

Therefore, the variety of foods ensures high quality protein intake and is the basis of vegetarianism and the fasting of the Orthodox Church. More specifically, we can say that legumes are foods rich in two amino acids, lysine and threonine, while poor in methionine. Rice like other cereals is rich in methionine. So cooking legumes with rice (e.g. $\varphi \alpha \kappa o ́ \rho v \zeta o$ ) or combining them with whole grain or rye bread covers the protein requirements. Also corn is poor in tryptophan and lysine and can be combined with legumes. Legumes can be combined with foods rich in vitamin C (such as peppers, tomatoes, orange), beta-carotene (e.g. carrots) and malic acid (e.g. white wine) as these substances increase absorption of non-heme iron containing legumes. That is why legumes are called the "meat" of fasting.

Reasonable consequence, the consumption of large quantities of vegetables, fruits, legumes, to provide in addition to the increased

${ }^{43}$ Bhagavan N.V., Ha C-E., Protein and Amino Acid Metabolism, chapter 15 in Essentials of Medical Biochemistry (Second Edition), 2015, pp 169-190.

${ }^{44}$ Fürst P., Stehle P., What are the essential elements needed for the determination of amino acid requirements in humans?, in "The Journal of Nutrition", vol. 134, 2004, pp. 1558S-1565S.

${ }^{45}$ Reeds P.J., Dispensable and indispensable amino acids for humans, in "The Journal of Nutrition", vol. 130, 2000, pp. 1835S-1840S. 
amount of fiber, and a large amount of vitamins and minerals. Therefore, when fasting is practiced without reckless excesses it can offer a complete diet.

\subsubsection{Calcium}

As it is known, the main source of calcium in developed countries is dairy products. But in fact we also find it in many vegetable foods such as green leafy vegetables (spinach, green beans, okra, lettuce, and parsley), broccoli, artichokes, cabbage, dried figs, orange, kiwi, white soy flour, walnut, chickpeas, beans, nuts, olives, almonds but also in seafood such as sardines, shrimp, cod, etc.

Vegetable foods are generally considered to provide the body with a small amount of calcium because calcium absorption can be affected by their content of oxalic acids and fiber or dietary fiber, such as spinach; preventing calcium absorption, while foods such as calcium, tahini, almonds and cabbage are low in oxalic acids and therefore their calcium is more easily absorbed ${ }^{46,47}$. The rate of absorption of calcium from milk is about $32 \%$, from cabbage $41 \%{ }^{48}$, from beans $22 \%{ }^{49}$, and $48 \%$ by broccoli ${ }^{50}$. Only high oxalate vegetables such as spinach have a low absorption rate of only $5 \%{ }^{51}$. For one serving of milk or milk products corresponds to $250 \mathrm{mg}$ of calcium equivalent to 5-6 servings of vegetables (leafy vegetables or dark green vegetables) or 10-12 servings of whole grains ${ }^{52}$.

While studies of a fasting sample in accordance with the rules of the Christian Orthodox Church have shown that lower calcium

${ }^{46}$ Weaver C.M., Calcium bioavailability and its relation to osteoporosis, in "Proceedings of the Society for Experimental Biology and Medicine", 1992; 200: 157-160.

${ }^{47}$ Caroli A., et al., Dairy intake and bone health: A viewpoint from the state of the art, in "Journal of Dairy Science", vol. 94, 2011, pp. 5249-5262.

${ }^{48}$ Heaney R.P., Weaver C.M., Calcium absorption from kale, in "American Journal of Clinical Nutrition", vol. 51, 1990, pp. 656-657.

${ }^{49}$ Weaver C.M., et al., Absorbability of calcium from common beans, in "Journal of Food Science", vol. 58, 1993, pp. 1401-1403.

${ }^{50}$ Heaney R.P., et al., Absorbability of calcium from brassica vegetables: broccoli, bok choy, and kale, in "Journal of Food Science", vol. 58, 1993, pp. 1378-1380.

${ }^{51}$ Heaney R.P., et al., Calcium absorbability from spinach, in "American Journal of Clinical Nutrition", vol. 47, 1988, pp. 707-709.

${ }^{52}$ Fulgoni V.L., et al., Determination of the optimal number of dairy servings to ensure a low prevalence of inadequate calcium intake in Americans, in "Journal of the American College of Nutrition", vol. 23, 2004, pp. 651-659. 
intake and lower dairy products consumption in fasters over 50 years, with long-term fasting (average fasting in 31 years), and in fasters who fasting from the childhood (average fasting at 14 years) caused no problems in their bone health ${ }^{53}$.

\subsubsection{Zinc}

It is indispensable for maintaining any form of life. Mammalian brain cells contain zinc, as well as salivary glands, the prostate, the immune system and the intestine. They are found in shellfish and to a lesser extent in animal proteins, beans, nuts, whole grains, and sunflower seeds. Vegetable fibers found in whole grain bread, cereals, vegetables and other products help to better absorb zinc.

A study comparing a nutritional fasting week of Lent with a week of non-fasting after Easter, as assessed by a food composition database and chemical analyses of 7-day weighed food samples, in monks from the area of Heraklion, Crete in Greece. They found that a slight increase in zinc was observed in the fasting week ${ }^{54}$. In another study, no significant difference was found between fasting and non-fasting zinc.

\subsubsection{Iron}

It is known that iron found in plant foods is low in bioavailability, i.e. it is absorbed in small amounts (14-18\% in mixed diets and $5-12 \%$ in vegetarian diets $)^{55}$. And this is because chelating complexes are formed in the intestinal lumen and are not as well absorbed as iron derived from foods of animal origin (15-35\% absorption of iron). The amount that will eventually be absorbed by the body depends on the other foods consumed in the same meal. More specifically: Foods that improve iron absorption are those that contain vitamin $\mathrm{C}$ and animal protein.

${ }^{53}$ Sarri K.O., Linardakis M., et al., Adipose DHA inversely associated with depression as measured by the Beck Depression Inventory, pp. 117-122.

${ }^{54}$ Papadaki A., Valsta L.M., et al., Differences in nutrient intake during a Greek Orthodox Christian fasting and non-fasting week, as assessed by a food composition database and chemical analyses of 7-day weighed food samples, in "Journal of Food Composition and Analysis", vol. 24, 2011, pp. 22-28.

${ }^{55}$ Hurrell R., Egli I., Iron Bioavailability and Dietary Reference Values, in "American Journal of Clinical Nutrition", vol. 91, 2010, pp. 1461S-1467S. 
On the other hand, foods containing calcium, tannins and polyphenols reduce iron absorption. Also, increased consumption of fresh fruits or vegetables rich in ascorbic acid, allows for increased absorption of non-heme iron ${ }^{56}$.

The findings from a study suggest that the fasting regimes of the Christian Orthodox Church do not adversely influence the iron status or increase the risk of anaemia. The data collected from 35 strict fasters and 24 non-fasters were studied before (pre) and near completion (end) of the Christmas fasting period. No subjects were detected with iron deficiency at the end of the Christmas fasting period. End dietary iron and fiber intake were significantly higher in the fasters as compared with the control group. In conclusion, adherence to the Orthodox Christian dietary guidelines does not have a major impact on iron status and is not associated with a significantly greater degree of iron deficiency ${ }^{57}$.

Also, a recent study has shown that iron deficiency has not been found in fasting, children and adolescents due to the frequent consumption of legumes, cereals and sometimes fish ${ }^{58}$.

Finally, in a recent study in Thessaloniki, Northen Greece; in healthy individuals who fasted during the Lent and Holy Week (48 days in total), where coagulation factors were tested, were found to be at normal levels as well as hematocrit and all post-hematological tests of fasting ${ }^{59}$.

\subsubsection{Vitamin D}

Generally, there is a lack of vitamin D intake in the human body due to the fact that few foods contain this vitamin in the presence of fats because it is a fat soluble vitamin. Such foods are fatty fish and eggs (in egg yolk) as well as foods that are enriched with vitamin D, such as e.g. milk and milk products in general, which contribute to $15 \%$ of dietary vitamin D etc. ${ }^{60}$ From our diet, vitamin D

${ }^{56}$ Gibson R.S., et al., Improving the bioavailability of nutrients in plant foods at the household level, in "Proceedings of the Nutrition Society", vol. 65, 2005, 160-168.

${ }^{57}$ Sarri K.O., et al., Is religious fasting related to iron status in Greek Orthodox Christians?, in "British Journal of Nutrition", vol. 94, 2005, pp. 198-203.

${ }^{58}$ Savva S.C., Kafatos A., Is red meat required for the prevention of iron deficiency children and adolescents?, in "Current Pediatric Reviews", vol. 10, 2014, pp. 177-183.

${ }^{59}$ Chryssochoou E., Linardakis M., et. al., The effect of Christian Orthdox Church fasting on the health and growth of children and adolescents [Article in Greek], pp. 121-129.

${ }^{60}$ Macdonald H.M., Contributions of Sunlight and Diet to Vitamin D Status, in "Calcified Tissue International", vol. 92, 2013, pp. 163-176. 
is provided in two forms, as vitamin D3 (cholecalciferol) and as vitamin D2 (ergocosiferol) ${ }^{61,62}$. A study in the elderly showed that fish make up the bulk of vitamin D intake, followed by cereals (with enriched breakfast cereals), meats and fat ${ }^{63}$. Several studies have shown that fish are an important source of food, as in Japan and Norway ${ }^{64}$. Also an important source of vitamin D is the mushrooms, especially those dried in the sun (100 grams is about 1600 IU D2) ${ }^{65}$. Finally, orange juice, enriched with vitamin D, is an essential source of vitamin D by absorbing both vitamins D2 and D3 equally ${ }^{66}$.

A study on fasting by the Christian Orthodox Church showed no difference in dietary vitamin $\mathrm{D}$ between fasting and non-fasting, not even in their blood tests ${ }^{67}$.

Although according to Holick's estimates, a few minutes in the sun can make 1,000 IU of vitamin D, which is four times more than 100 grams of fatty fish. It is suggested that sunlight accounts for $90 \%$ of vitamin D and diet only $10 \%$, although this varies, mainly depending on location ${ }^{68}$.

As in Greece, for example, where sunshine is much higher each year compared to a northern country in Scandinavia, the paradox is that there is also a general lack of vitamin D in Greece.

${ }^{61}$ Armas L.A., Hollis B.W., Heaney R.P., Vitamin D2 is much less effective than vitamin D3 in humans, in "Journal of Clinical Endocrinology \& Metabolism", vol. 89, 2004, pp. 5387-5391.

${ }^{62}$ Biancuzzo R.M., Young A., et al., Fortification of orange juice with vitamin D2 or vitamin D3 is as effective as an oral supplement in maintaining vitamin D status in adults, in "American Journal of Clininical Nutrution", vol. 91, 2010, pp. 1621-1626.

${ }^{63}$ Hoare J., et al., The Dietary and Nutritional Survey of British adults aged 19-64 years. Summary report. Social Survey Division of the Office of Population Censuses and Surveys (OPCS) with dietary and nutritional evaluation by the Ministry of Agriculture Fisheries and Foods (MAFF), and the Department of Health, 2004, TSO, London.

${ }^{64}$ Calvo M.S., Whiting S.J., Barton C.N., Vitamin D intake: a global perspective of current status, in "Journal of Nutrition", vol. 135, 2005, pp. 310-316.

${ }^{65}$ Holick M.F., Vitamin D deficiency, in "New England Journal of Medicine", vol. 357, 2007, pp. 266-281.

${ }^{66}$ Hoare J., et al., The Dietary and Nutritional Survey of British adults aged 19-64 years.

${ }^{67}$ Rodopaios N.E., Manolarakis G.E., et al., The significant effect on musculoskeletal metabolism and bone density of the Eastern Mediterranean Christian Orthodox Church fasting.

${ }^{68}$ Kimlin M.G., Geographic location and vitamin D synthesis, "Molecular Aspects of Medicine", vol. 29, 2008, pp. 453-461. 
The problem becomes even greater for priests and monks because of clothing, where the whole body and limbs should be covered by garments all of the year.

A study has shown that the intake of dietary and pharmaceutical supplements in nuns may cover potential deficiencies of vitamin $\mathrm{D}^{69}$.

\subsubsection{Vitamin B12}

Foods are found mainly in protein-bound as well as in free form. It is mainly found in animal foods so it is usually observed after periods of fasting. The liver stores $60 \%$ of the body's total B12 (2-5 mg). Exactly, because there are stores of this vitamin in the body and the required daily intake is $2.4 \mu \mathrm{g}$ for adults, we could conclude that even a relatively low intake of this vitamin for 40 days fasting does not result in a corresponding lack of it, provided how in non-fasting times the person follows a balanced diet.

Research on monks where the chemical analysis of weekly weighted fasting and non-fasting food was analyzed found a small difference in B12 intake between the two periods, with greater intake in the fasting period ${ }^{70}$.

Another study that examined dietary intake also the B12 in both fasters and non-fasters, at the beginning and at the end of the fasting period, was found to be at normal levels at the beginning, while at the end of the fasting it was reduced.

This is of course improved very easily by the increased consumption of animal products in the "free periods", that is, in the days after fasting for a long time, where all food is allowed.

Sources of B12 include whole dairy, liver, red meat, cheese, eggs and some fish such as sardines, herring, mackerel, salmon, eel, trout, tuna, cod and shellfish (mussels, etc.). Also, fortified breakfast cereals are a very valuable source of vitamin B12. Few vegetables provide a small amount of B12, provided they are enriched during cultivation (broccoli, asparagus, spinach, etc.) or during vegetation (soybeans, radish, etc.). The bioavailability ${ }^{71}$ of vitamin B12 in healthy humans from fish, sheep and chicken meat is on average $42 \%, 56 \%-89 \%$ and $61 \%-66 \%$, respectively. While vitamin B12 in eggs seems to be poorly absorbed $(<9 \%)$ in relation to other animal

${ }^{69}$ Rodopaios N.E., Manolarakis G.E., et al., The significant effect on musculoske-letal metabolism and bone density of the Eastern Mediterranean Christian Orthodox Church fasting.

${ }^{70}$ Hurrell R., Egli I., Iron Bioavailability and Dietary Reference Values, pp. 1461S-1467S.

${ }^{71}$ Bioavailability is the rate of absorption of a substance obtained from an organism. 
products $^{72}$. Recent review research has shown that there was no deficiency or inadequate vitamin B12 intake among fasters ${ }^{73}$.

\section{Conclusion}

Generally, during the fasting period, lower intakes of total and saturated fat and trans fatty acids and higher intake of dietary fiber, iron and increased intake of legumes and fish / seafood were observed. Calcium intake was lower in the fasting period, while dairy and egg consumption increased significantly in the non-fasting week, as a study to monks of two Monasteries of Heraklion in Crete, showed ${ }^{74}$.

Similar results have been shown in a recent study, where during fasting periods there was a reduction in calorie and fat (total and saturated), with increased carbohydrate and fiber intake, thereby reducing body weight and cholesterol levels (total and LDL cholesterol) in the blood. The intake of most antioxidant vitamins and minerals does not appear to change during fasting and there is an increased intake of magnesium and folic acid ${ }^{75}$.

The intake of total fat, saturated fat and trans fatty acids is lower in both adult and child fasters, while intake of protective nutrients such as vitamin C, folate, magnesium, and fiber is higher and provides protection from several chronic diseases, as a review study on fasting by the Christian Orthodox Church demonstrates. Data retrieved suggest that, compared with non-fasters, adult and child fasters enjoy better dietary quality and have healthier blood lipid profiles ${ }^{76}$.

In conclusion, the dietary guidelines of our church are unique worldwide, as noted by a foreign scientist G. Cannon in an article in the journal Public Health Nutrition, which states that The Orthodox Church is an extremely important and unique work in education in the world Nutrition ${ }^{77}$.

${ }^{72}$ Watanabe F., Vitamin $B_{12}$ Sources and Bioavailability, in "Experimental Biology Medicine", vol. 232, 2020, pp. 1266-1274.

${ }^{73}$ Koufakis T., Karras S.K, et al., Effects of Orthodox religious fasting on human health: a systematic review, in "European Journal of Nutrition", vol. 56, 2017, pp. 2439-2455.

${ }^{74}$ Low Density Lipoprotein (LDL) cholesterol is often called the "bad" cholesterol because it collects in the walls of your blood vessels, raising your chances of health problems like a heart attack or stroke.

${ }^{75}$ Cannon G., Out of the Christmas Box, in "Public Health Nutrition", vol. 7, 2004, pp. 987-990.

${ }^{76}$ Sabate J., Religion, diet and research, pp. 199-201.

${ }^{77}$ Cannon G., Out of the Christmas Box, vol. 7, 2004, pp. 987-990. 